IJBPAS, December, Special Issue, 2021, 10(12): 445-453

ISSN: 2277-4998

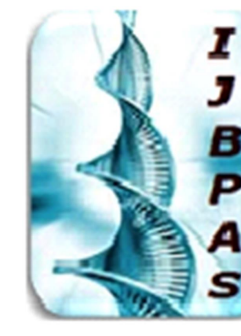

International Journal of Biology, Pharmacy

and Allied Sciences (IJBPAS)

'A Bridge Betueen caboratory and QRendo'

WwW.ijbas.com

\title{
EPIDEMIC MODELS AND PREDICTION OF HERD IMMUNITY AGAINST COVID-19
}

\section{SHISHIR KUMAR JHA}

Ramjas College, University of Delhi, Delhi 110007 (India)

*Corresponding Author: Shishir Kumar Jha: E Mail: skjha statistics@ramjas.du.ac.in

Received $19^{\text {th }}$ Aug. 2021; Revised $20^{\text {th }}$ Sept. 2021; Accepted $29^{\text {th }}$ Oct. 2021; Available online $1^{\text {st }}$ Dec. 2021

https://doi.org/10.31032/IJBPAS/2021/10.12.2041

\begin{abstract}
Destructions due to COVID-19 pandemic have been widespread affecting each and every segment of the society globally. The spreading process of the disease is difficult to understand without the correct structure of a mathematical framework. The conventional epidemic models are based on assumptions that appear unrealistic in the case of analysing the impact of SARS-CoV-2 virus. Asymptomatic infected persons have been found to be super spreader in the case of COVID-19 epidemic. In this study an effort has been made to construct modified SIS and SIR epidemic models to accommodate such cases. Achieving herd immunity to get rid of the epidemic is difficult to realize because of slow pace of vaccination. Minimum proportion of immune population to arrive at herd immunity has been estimated under different assumptions on average age of attack of the disease.
\end{abstract}

Keywords: Herd immunity, Infective, SARS-CoV-2, SIR model, Susceptible

\section{INTRODUCTION}

Genesis of an epidemic can be tracked down to ancient Greeks (459-377 B.C.).

The evolution of the word epidemic including the terms immunity, infections and epidemiology at the time of Hippocrates is described in many investigations $[\mathbf{1}, \mathbf{2}]$. The study of components influencing the frequency or incidence of communicable or noncommunicable diseases is described as epidemiology. Similarly, wide spread presence of an infectious disease over a large part of the globe at a particular point of time is referred as pandemic. Mathematical modelling to study the features of epidemics can be traced back to 
the first half of $20^{\text {th }}$ century while analysing the spread of malaria and measles [3, 4]. It was assumed that population consists of sub-populations, namely, susceptible, infected and immune. In the second half of $20^{\text {th }}$ century a model to analyse carrier-borne epidemics assuming that only carriers are responsible for spreading of the disease was proposed [5]. The concept of role of carriers in spreading the disease was further expanded [6]. The agents responsible for infectious diseases are either viruses (e.g. SARS-CoV-2, HIV, Measles, Influenza, Chickenpox, Dengue fever etc.), bacteria (e.g. Tuberculosis, Pneumonia, Plague etc.) or protozoa (Syphillis, Malaria etc.). Transmission of virus, bacteria or protozoa may be from person to person; person to environment and then environment to person; reservoir to vector, vector to person, person to reservoir and reservoir to person.

SARS-CoV-2 virus spreads from person to person or person to environment and environment to person. It spread across countries and infected a large proportion of population resulting in deaths and sufferings all over the world, therefore, rightly declared as pandemic. Similarly, Plague, cholera and Influenza were declared as pandemic in the past. Vaccines have significant impact on lowering the intensity of the disease but not able to suppress the mushrooming of the disease. Developing mathematical model to study the impact of epidemic is complex because a susceptible can acquire infection from an infective and an infected person can be cured. Further, a cured person can join the susceptible group. A study on SARS-CoV-2 in the year 2020 with natives of Italy found that majority of the people are asymptotic with no symptoms but are contributing in spreading the disease [7]. Such type of people can be included in the model for proper analysis and prediction of the disease. Mathematical epidemic models SIS, SIR and SIRS were formulated to study the features of the epidemic $[8,9]$. In SIS $(S \rightarrow I \rightarrow S)$ model, recovery is not a guarantee of immunity. If immunity is achieved after recovery, then we have SIR $(\mathrm{S} \rightarrow \mathrm{I} \rightarrow \mathrm{R})$ model. However, recovery may be for a short span and recovered population becomes susceptible again and in this case SIRS $(\mathrm{S} \rightarrow \mathrm{I} \rightarrow \mathrm{R} \rightarrow \mathrm{S})$ model may be used to describe the epidemic. Since, the infected persons can be both symptomatic and asymptomatic, which is true for the epidemic COVID-19, therefore the standard epidemic models may be revised to examine the growth of the disease.

MATHEMATICAL MODELLING 
Because of mysterious nature of SARS-

CoV-2 virus, a complex mathematical modelling for understanding the COVID19 impact is required to study the intensity of the disease by including asymptotic cases also.

\section{Notations and assumptions}

Suppose, $\mathrm{P}$ denotes the population under consideration, which is assumed to be constant. Further, suppose that $\mathrm{P}$ is the sum of disjoint classes (sub-populations). These sub-populations are continuous variables and change with time $(\mathrm{t})$. Further, let $S(t), I(t), I_{A}(t), I_{S}(t)$ and $R(t)$ denote fractions of susceptible, infectives, infectives (asymptomatic), infectives (symptomatic) and recovered at time $t$ of the population $\mathrm{P}$ respectively with $\mathrm{I}(\mathrm{t})=$ $I_{A}(t)+I_{S}(t)$.

Let $\alpha, \lambda$ and $\mu$ denote the average contact rate, recovery rate and daily usual death rate respectively. $\mu$ is proportional to the class size.

$\Rightarrow \alpha \mathrm{S}=$ mean number of susceptible infected per day.

$\Rightarrow$ mean of susceptible getting infection by asymptomatic infected population $\left(\mathrm{I}_{\mathrm{A}}\right)$ per day $=\left(\mathrm{I}_{\mathrm{A}}\right) \alpha \mathrm{S}$ and mean number of susceptible getting infection by the symptomatic infected population $\left(\mathrm{I}_{S}\right)$ per day $=\left(\mathrm{I}_{\mathrm{S}}\right) \alpha \mathrm{S}$.

$\Rightarrow$ Mean of the susceptible getting infection by infected population $=\left(\mathrm{I}_{\mathrm{A}}\right) \alpha \mathrm{S}$ $+\left(\mathrm{I}_{\mathrm{S}}\right) \alpha \mathrm{S}$

$=\left(\mathrm{I}_{\mathrm{A}}+\mathrm{I}_{\mathrm{S}}\right) \alpha \mathrm{S}=\mathrm{I} \alpha \mathrm{S}$

Since, $\lambda$ is the recovery removal rate, therefore, proportion of observations exposed at time 0 and found to be infected at time $\mathrm{t}$ can be taken as $e^{\lambda t}$ following Hethcote et. al. (1981c). So, the mean infectivity time $=1 / \lambda$.

Therefore, removal rate (combining recovery and death) $=\lambda+\mu$

$\Rightarrow \frac{\alpha}{\lambda+\mu}=\beta$ (average contacts with susceptible by an infected person) is reproduction rate.

$\Rightarrow \beta S=Y($ say $)$ is the replacement number, i.e. mean number of susceptible contacting an infective [10].

\section{Modified SIS model}

Infected persons can be symptomatic or asymptomatic. Therefore, the modified SIS model, which does not guarantee the immunity can be formulated as

$$
\begin{aligned}
& S^{\prime}(t)=\frac{d S(t)}{d t}=-\alpha S(t)\left[I_{A}(t)+I_{S}(t)\right]+\lambda\left[I_{A}(t)+I_{S}(t)\right]+\mu[1-S(t)] \\
& I^{\prime}(t)=\frac{d(t)}{d t}=\alpha S(t)\left[I_{A}(t)+I_{S}(t)\right]-\lambda\left[I_{A}(t)+I_{S}(t)\right]-\mu\left[I_{A}(t)+I_{S}(t)\right]
\end{aligned}
$$

Such that $\mathrm{S}(0)>0, \mathrm{I}_{\mathrm{A}}(0), \mathrm{I}_{\mathrm{S}}(\mathrm{t})>0$ and $\mathrm{S}(\mathrm{t})+\mathrm{I}(\mathrm{t})=1$ for all $\mathrm{t}$.

Since, $S(t)=1-I(t)=1-\left[I_{A}(t)+I_{S}(t)\right]$

Therefore, 


$$
\begin{aligned}
I^{\prime}(t) & =\alpha[1-I(t)] I(t)-\lambda I(t)-\mu I(t) \\
& =[\alpha-(\lambda+\mu)] I(t)-\alpha[I(t)]^{2} ; \quad I(0)>0
\end{aligned}
$$

Solving the differential equation (2), we get;

$$
\begin{array}{rlrl}
I(t) & =\frac{e^{(\lambda+\mu)(\beta-1) t}}{\left\{\beta\left[e^{((\lambda+\mu)(\beta-1) t}-1\right] /(\beta-1)\right\}+1 / I(0)} & & \text { for } \beta \neq 1 \\
& =\frac{1}{\alpha t+[1 / I(0)]} & & \text { for } \beta=1 \\
\text { For } t \rightarrow \infty, I(t) \rightarrow \frac{\beta-1}{\beta}=1-\frac{1}{\beta} & \text { for } \beta \neq 1 \\
\text { and } I(t) \rightarrow 0 & \text { for } \beta=1
\end{array}
$$

From the findings of eq. (4), we conclude $\quad \Rightarrow$ if recovery

that if $\beta$ (i.e. reproduction rate) exceeds 1 and death rates tend to zero then every then the infection becomes endemic, person will be infected in course of time. otherwise with the passage of time disease Therefore, in the case of $(\lambda=0=\mu)$, the will come to an end.

Similarly, if $\lambda=0=\mu$, then from eq. (3),

we get $I(t)=\infty$

model is called a simple epidemic model [11].

The wide spread epidemic generally lasts for more than one year (e.g. COVID-19).

\section{Modified SIR model}

should be included in the epidemic model and considered as new susceptible. Therefore, vital events (birth and death) Similarly, natural deaths in each class should be included in the study. Birth should get a place in the model.

Therefore, the model,

$$
\begin{aligned}
\mathrm{S}^{\prime}(\mathrm{t}) & =\frac{\mathrm{dS}(\mathrm{t})}{\mathrm{dt}}=-\alpha \mathrm{S}(\mathrm{t})\left[\mathrm{I}_{\mathrm{A}}(\mathrm{t})+\mathrm{I}_{\mathrm{S}}(\mathrm{t})\right]+\mu[1-\mathrm{S}(\mathrm{t})] \\
\mathrm{I}^{\prime}(\mathrm{t}) & =\frac{\mathrm{d}(\mathrm{t})}{\mathrm{dt}}=\alpha \mathrm{S}(\mathrm{t})\left[\mathrm{I}_{\mathrm{A}}(\mathrm{t})+\mathrm{I}_{\mathrm{S}}(\mathrm{t})\right]-(\lambda+\mu)\left[\mathrm{I}_{\mathrm{A}}(t)+\mathrm{I}_{\mathrm{S}}(t)\right] \\
\Rightarrow \mathrm{S}^{\prime}(\mathrm{t}) & =\frac{\mathrm{dS}(\mathrm{t})}{\mathrm{dt}}=-\alpha \mathrm{SI}+\mu(1-\mathrm{S}) \\
\mathrm{I}^{\prime}(\mathrm{t}) & =\frac{\mathrm{dI}(\mathrm{t})}{\mathrm{dt}}=\alpha \mathrm{S} \mathrm{I}-(\lambda+\mu) \mathrm{I} \text { such that } \mathrm{S}(0)>0, \mathrm{I}(0)>0
\end{aligned}
$$

A case study of Isfahan in 2021 in forecasting COVID-19 epidemic using SIR model by some researchers was carried out [12]. The predicted values were compared with the next six months actual data. It was established that the model simulates the pattern only for succeeding three to four months and then it behaves in dissimilar style. Even Modified SIR model using first few months of 2020 COVID-19 data could not predict the next wave of the disease correctly [13]. Because of the following reasons, SIR model or modified 
SIR model could not predict the surge correctly.

(1) Assuming population to be closed is not realistic.

(2) Assuming compete isolation of infected persons is also not followed.

(3) Assuming recovered population to be immunized is not true.

(4) Model does not include asymptomatic cases, which may be spreading the disease as frequently as symptomatic cases.
It is not easy to trace asymptomatic infected cases contributing to the constant effect on the model resulting in escalation of epidemic. In such situations, epidemic is bound to grow at exponential rate. Therefore, modified SIR model should include variables for asymptomatic and symptomatic cases separately to get realistic estimate of the parameters of the epidemic. So, the SIR model without incorporating the vital events is

$$
\begin{aligned}
& \mathrm{S}^{\prime}(\mathrm{t})=\frac{\mathrm{dS}(\mathrm{t})}{\mathrm{dt}}=-\alpha \mathrm{S}(\mathrm{t})\left[\mathrm{I}_{\mathrm{A}}(\mathrm{t})\right]-\alpha^{\prime} \mathrm{S}(\mathrm{t}) \mathrm{I}_{\mathrm{S}}(\mathrm{t}) \\
& \mathrm{I}^{\prime}(\mathrm{t})=\frac{\mathrm{dI}(\mathrm{t})}{\mathrm{dt}}=\alpha \mathrm{S}(\mathrm{t})\left[\mathrm{I}_{\mathrm{A}}(\mathrm{t})\right]+\alpha^{\prime} \mathrm{S}(\mathrm{t}) \mathrm{I}_{\mathrm{S}}(\mathrm{t})-\lambda\left[\mathrm{I}_{\mathrm{A}}(\mathrm{t})\right]-\lambda^{\prime} \mathrm{I}_{\mathrm{S}}(\mathrm{t}) \\
& \mathrm{R}^{\prime}(\mathrm{t})=\frac{\mathrm{dR}(\mathrm{t})}{\mathrm{dt}}=\lambda\left[\mathrm{I}_{\mathrm{A}}(\mathrm{t})\right]+\lambda^{\prime} \mathrm{I}_{\mathrm{S}}(\mathrm{t})
\end{aligned}
$$

with $\mathrm{S}(0)>0, \mathrm{I}(0)>0$ and $\mathrm{R}(0)>0 ; \mathrm{S}(\mathrm{t})+\mathrm{I}_{\mathrm{A}}(\mathrm{t})+\mathrm{I}_{\mathrm{S}}(\mathrm{t})+\mathrm{R}(\mathrm{t})=1$ for all $\mathrm{t}$.

$$
\Rightarrow \mathrm{R}(\mathrm{t})=1-\mathrm{S}(\mathrm{t})-\mathrm{I}_{\mathrm{A}}(\mathrm{t})-\mathrm{I}_{\mathrm{S}}(\mathrm{t})
$$

where $\alpha$ and $\alpha^{\prime}$ are average contact rates with the asymptomatic and symptomatic infected populations respectively. $\lambda$ and $\lambda^{\prime}$ are recovery rates of an asymptomatic infectives and symptomatic infectives respectively.

Let $\frac{\alpha}{\lambda}=\beta$ and $\frac{\alpha^{\prime}}{\lambda^{\prime}}=\beta^{\prime}$ be the asymptomatic and symptomatic infected person's average contact with the susceptible respectively. Therefore, $\beta S(t)$ and $\beta^{\prime} S(t)$ are average susceptible population contacting asymptomatic and symptomatic infectives at time $t$ respectively.
Solving eq. (6) and using the fact $\mathrm{S}(\mathrm{t})+$ $\mathrm{I}_{\mathrm{A}}(\mathrm{t})+\mathrm{I}_{\mathrm{S}}(\mathrm{t})+\mathrm{R}(\mathrm{t})=1$, we estimate $\alpha$, $\alpha^{\prime}, \lambda$ and $\lambda^{\prime}$ and hence $\beta$ and $\beta^{\prime}$.

In standard SIR model, recovered population is assumed to be immune, which is not supportive of the fact. Immunity may last only for a limited span of time and there is every possibility of recovered population becoming susceptible after some time. The same is the case with the vaccinated population.

Models proposed by Cooper and Ahmetolan ignored the vital events assuming that the epidemic is for short 
period of time (less than one year) $[13$,

14]. If epidemic lasts for more than one year then the model must include vital dynamics (i.e. vital events, birth and death), therefore the modified epidemic model is

$$
\begin{aligned}
& S^{\prime}(t)=\frac{d S(t)}{d t}=-S(t)\left[\alpha I_{A}(t)+\alpha^{\prime} I_{S}(t)\right]+\mu[1-S(t)] \\
& \left.I^{\prime}(t)=\frac{d I(t)}{d t}=S(t)\left[\alpha I_{A}(t)\right]+\alpha^{\prime} I_{S}(t)\right]-\left[\lambda I_{A}(t)+\lambda^{\prime} I_{S}(t)\right]-\mu\left[I_{A}(t)+I_{S}(t)\right] \\
& R^{\prime}(t)=\frac{d R(t)}{d t}=\left[\lambda I_{A}(t)+\lambda^{\prime} I_{S}(t)\right]-\mu R(t)
\end{aligned}
$$

where, $\alpha, \alpha^{\prime}, \lambda, \lambda^{\prime}$ and $\mu$ are positive constants with $\mathrm{S}(0)>0, \mathrm{I}(0)>0$ and

$$
R(t)=1-S(t)-I_{A}(t)-I_{S}(t) .
$$

The formula to estimate $\beta$ for unvaccinated homogeneous population is

$$
\hat{\beta}=1+\frac{\gamma}{A} \quad \text { (8) }[15]
$$

where, $\gamma$ and $\mathrm{A}$ are average life time and average age at which the epidemic attacks respectively.

\section{CALCULATION OF HERD IMMUNITY}

Herd immunity for a disease in the population is achieved if a large proportion of population are immune because of developing antibody to fight the disease either after getting vaccinated or after recovery from the disease.

Suppose, V is the proportion of population, who have achieved immunity because of vaccination and $\mathrm{W}$ is the proportion of population, who have achieved immunity because of recovery from the disease.

Therefore, proportion of immune population $=\mathrm{V}+\mathrm{W}=\rho$ (say)

$$
\begin{aligned}
& \because \rho=1-\mathrm{S}(\mathrm{t})-\mathrm{I}(\mathrm{t}) \text {, where } \mathrm{I}(\mathrm{t})=\mathrm{I}_{\mathrm{A}}(\mathrm{t})+\mathrm{I}_{\mathrm{S}}(\mathrm{t}) \\
& \therefore \mathrm{S}(\mathrm{t})=1-\rho \text { if } \mathrm{I}(\mathrm{t})=0 \\
& \Rightarrow \text { For herd immunity } \beta(1-\rho)<1 \Rightarrow \rho>1-\frac{1}{\beta} \\
& \quad \Rightarrow \text { If } \beta=1 \text { then } \rho>0 \text { (i.e. there is no epidemic). }
\end{aligned}
$$

If $\beta=2$ then $\rho>\left(1-\frac{1}{2}\right)=0.5 \Rightarrow$ For achieving herd immunity at least $50 \%$ population need to be immune.

If $\beta=5$ then $\rho>\left(1-\frac{1}{5}\right)=0.8 \Rightarrow$ For achieving herd immunity at least $80 \%$ population need to be immune.

If $\beta=10$ then $\rho>\left(1-\frac{1}{10}\right)=0.9 \Rightarrow$ For achieving herd immunity at least $90 \%$ population need to be immune.

These findings seem to be quite natural contributes to spread of the disease because increase in contact number Attaining herd immunity is very difficult 
to achieve in large population because even if high percentage of vaccination is met, it is not distributed uniformly among the population. This is evident from the past experience of small pox epidemic. Small pox was eradicated from developed

countries in 1958 but it was eradicated from developing Nations in 1980's [16].

Value of minimum $\rho$ (proportion of immune population) to achieve the herd immunity in India for SARS-CoV-2 virus has been calculated using eq. (9) and shown in table 1 [17].

Table 1

\begin{tabular}{|c|c|c|c|c|}
\hline $\begin{array}{c}\text { Vaccinated age } \\
\text { group }\end{array}$ & $\begin{array}{c}\text { A } \\
\text { (Average age of } \\
\text { attack) }\end{array}$ & $\begin{array}{c}\gamma \\
\text { (Average life time) }\end{array}$ & $\begin{array}{c}\widehat{\boldsymbol{\beta}}=\mathbf{1}+\frac{\gamma}{A} \\
\text { (Average no. of } \\
\text { contact) }\end{array}$ & $\begin{array}{c}\text { Minimum } \rho \text { for herd } \\
\text { immunity }\end{array}$ \\
\hline $60+$ & $\mathbf{5 0}$ & $\mathbf{7 0}$ & $\mathbf{2 . 4 0}$ & $\mathbf{0 . 5 8}$ \\
\hline $60+$ & $\mathbf{4 5}$ & $\mathbf{7 0}$ & $\mathbf{2 . 5 6}$ & $\mathbf{0 . 6 1}$ \\
\hline $60+$ & $\mathbf{4 0}$ & $\mathbf{7 0}$ & $\mathbf{2 . 7 5}$ & $\mathbf{0 . 6 4}$ \\
\hline $60+$ & $\mathbf{3 5}$ & $\mathbf{7 0}$ & $\mathbf{3 . 0 0}$ & $\mathbf{0 . 6 7}$ \\
\hline $45+$ & $\mathbf{3 0}$ & $\mathbf{7 0}$ & $\mathbf{3 . 3 3}$ & $\mathbf{0 . 7 0}$ \\
\hline $45+$ & $\mathbf{2 5}$ & $\mathbf{7 0}$ & $\mathbf{3 . 8 0}$ & $\mathbf{0 . 7 8}$ \\
\hline $45+$ & $\mathbf{2 0}$ & $\mathbf{7 0}$ & $\mathbf{4 . 5 0}$ & $\mathbf{0 . 8 2}$ \\
\hline $18+$ & $\mathbf{1 5}$ & $\mathbf{7 0}$ & $\mathbf{5 . 6 7}$ & $\mathbf{0 . 8 7 5}$ \\
\hline $15+$ & $\mathbf{1 0}$ & $\mathbf{7 0}$ & $\mathbf{8 . 0 0}$ & \\
\hline
\end{tabular}

Assuming that elderly people are more vulnerable to Covid-19 virus, $60+$ agegroup population were vaccinated in the first phase in India. Further, assume that $60+$ age-group population got the immunity for the next few months and also assume that younger population have low chance of severe infection. From the table 1 , we see that the minimum $\rho$ for herd immunity is 0.58 (i.e. herd immunity occurs if at least $58 \%$ of the homogeneously mixing population is immune) in the case of $\mathrm{A}$ is 50 and the minimum $\rho$ for herd immunity is 0.64 if $\mathrm{A}$ is 40 .

Similarly, when $45+$ age-group population were vaccinated then the minimum $\rho$ for herd immunity is 0.70 under the assumption that the average age at which epidemic attacks is 30 (i.e. herd immunity occurs if at least $70 \%$ of the homogeneously mixing population is immune). If the average age of attack of the COVID-19 virus is 20 then the herd immunity will be achieved at $\rho=0.78$.

Suppose that young population are also susceptible and a large number of $18+$ agegroup population developed anti bodies leading to immunity for the virus after getting vaccinated or getting cure after infection. In this scenario, if the average age of attack of COVID-19 virus is 15 then the herd immunity will be achieved at $\rho=$ 0.82. Therefore, herd immunity will be achieved only if at least $82 \%$ of the homogeneously mixing population is 
immune. Similarly, if a large number of $15+$ age-group population developed anti bodies leading to immunity for the virus after getting vaccinated or getting cure after infection and the average age of attack of COVID-19 virus is 10 then the minimum $\rho$ for herd immunity is 0.875 .

\section{CONCLUSION}

The modified SIS model and the modified SIR model as described in sections 2(ii) and 2(iii) with vital dynamics show that the epidemic disappears if contact number $\beta$ is less than 1 and become endemic in the case of $\beta$ exceeds 1. The modified SIR epidemic model without considering the impact of vital events (birth and death) is suitable for analysing the epidemic outbreak lasting for less than one year, whereas the modified SIR epidemic model is proper for the epidemic outbreaks lasting for longer period of time. Herd immunity for a disease is achieved, when a sufficient proportion of population become immune to an infection. Attaining herd immunity for a disease is very difficult for large and non-homogeneous population. In the case of highly infectious disease such as COVID-19, which can infect all age-group people, findings of table 1 clearly indicates that a very high percentage of population must be immune in a short span of time to attain herd immunity. Otherwise, immune population keep on adding the number of susceptible resulting in endemic situation of the disease. Table 1 shows that the average age onset of epidemic is inversely proportional to fraction of immune population.

\section{REFERENCES}

[1] Martin, P. M. V. and Martin-Granel, E. 2500-year evolution of the term epidemic. Emerging Infectious Diseases. 2006; 12(6): 976-980.

[2] Pappas, G., Kiriaze, I.J. and Falagas, M. E. Insights into infectious diseases in the era of Hippocrates. International Journal of Infectious Diseases. 2008; 12, 347-350.

[3] Ross, R. The prevention of malaria, $2^{\text {nd }}$ ed. Murray, London; 1911.

[4] Bartlett, M. S. Measles periodicity and community size. Journal of the Royal Statistical Society, Series A. 1957; 120(1), 4870.

[5] Weiss, G. H. On the spread of epidemics by carriers. Biometrics. 1965; 21, 481-490.

[6] Routleff, C. A variation of Weiss's carrierborne epidemic model. Journal of Applied Probability. 1982; 19(2), 403-407.

[7] Giordano, G., Blanchini, F., Bruno, R., Colaneri, P., Filippo, A. D., Matteo, A. D. and Colaneri, M. Modelling the COVID-19 epidemic and implementation of populationwide interventions in Italy. Nature Medicine. $2020 ; 26,855-860$

[8] Hethcote, H. W. Qualitative analysis for communicable disease models. Math. Biosci. $1976 ; 28,335-356$. 
[9] Hethcote, H. W., Stetch, H. W. and Van den Driessche, P. Nonlinear oscillations in epidemic models. SIAM J. Appl. Math. 1981a; $40,1-9$.

[10] Hethcote, H. W. Three basic epidemiological models. Applied Mathematical Ecology, Biomathematics. 18, 119-144. Springer, Berlin, Heidelberg, New York; 1989

[11] Bailey, N. T. J. The mathematical theory of infectious diseases and its applications, $2^{\text {nd }}$ ed. Hafner Press, New York; 1975.

[12] Moein, S. et. al. Inefficiency of SIR models in forecasting COVID-19 epidemic: a case study of Isfahan. Scientific Reports. 2021; 11,4725 .

[13] Cooper, I., Mondal, A. and Antonopoulos, C. G. A SIR model assumption for the spread of C0VID-19 in different communities. Chaos, Solitons and Fractals. 2020; 139, 110057.

[14] Ahmetolan, S., Bilge, A. H., Demrci, A., Peker-Dobie, A. and Ergonul, O. What can we estimate from fatality and infectious case data using the susceptible-infected-removed (SIR) model? A case study of covid-19 pandemic. Frontiers in medicine. 2020; https://doi.org/10.3389/fmed.2020.556366

[15] Dietz, K. Transmission and control of arbovirus diseases. Proceedings of SIMS Conference of Epidemiology. 1975; 104-121.

[16] World Health Organization. The global eradication of small pox, Final report. WHO, Geneva; 1980.

[17] Anderson, R. M. Population dynamics of infectious diseases: Theory and applications. 1-37. Chapman and Hall, New York; 1982. 